\title{
The unbalance of adiponectin oligomers, RvE1 and chemerin levels are associate with increase of adiposopathy status and insulin resistance in obesity
}

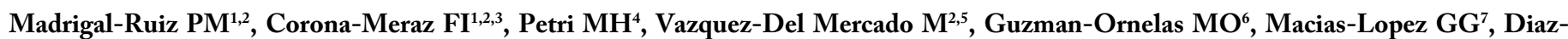
Rubio $\mathrm{GI}^{2}$ and Navarro-Hernandez $\mathrm{RE}^{1,2 *}$

${ }^{1}$ UDG-CA-701, Grupo de Investigacion Inmunometabolismo en Enfermedades Emergentes, Centro Universitario de Ciencias de la Salud, Universidad de Guadalajara, Sierra Mojada No. 950, Colonia Independencia, C.P. 44340. Guadalajara, Jal., Mexico

${ }_{2}^{2}$ Instituto de Investigacion en Reumatologia y del Sistema Músculo Esquel etico, Centro Universitario de Ciencias de la Salud, Universidad de Guadalajara, Sierra Mojada No. 950, Colonia Independencia, C.P. 44340. Guadalajara, Jal., Mexico

${ }^{3}$ Departamento de la Salud Poblacional. Division de Ciencias de la Salud, Centro Universitario de Tonalá. Campus CUTonalá Av. Nuevo Perif erico No. 555, C.P. 45425, Tonalá Jalisco, Mexico

${ }^{4}$ Vascular center, Skane University Hospital, Malmö, Sweden

${ }^{5}$ Hospital Civil Dr. Juan I, Menchaca, Division de Medicina Interna, Servicio de Reumatologia, 004086 PNPC, CONACyT, Salvador Quevedo y Zubieta SN, 44340, Guadalajara, Jalisco, Mexico

${ }^{6}$ Departamento de Salud-Enfermedad como proceso individual. División de Ciencias de la Salud, Centro Universitario de Tonalá. Campus CUTonalá Av. Nuevo Perif erico No. 555, C.P. 45425, Tonala Jalisco, Mexico

'UDG-CA-817 Investigacion genomica y biom edica. Departamento de Farmacobiologia, Centro Universitario de Ciencias Exactas e Ingenierias, Universidad de Guadalajara, Boulevard Marcelino Garcia Barragán No. 1421, C.P. 44430. Guadalajara, Jal, Mexico

\begin{abstract}
Objective: The aim was to establish if the balance adiponectin-oligomers, resolvin-E1 and chemerin levels could contribute to the insulin resistance (IR) setting of subjects with obesity, based on their serum levels and its relationship with inflammatory markers, metabolic profile and adiposopathy status.

Methods: This study included 230 individuals, classified according to World Health Organization criteria by body mass index (BMI) $\mathrm{kg} / \mathrm{m}^{2}$ in two groups: withoutobesity (from 18.5 to 29.9) and with-obesity (from 30.0 to 39.9). Body fat mass distribution, metabolic and inflammatory markers were measured by anthropometric, enzymatic and immuno-turbidimetry methods, respectively. Serum insulin, resolvin-E1, chemerin, and adiponectin-oligomers were evaluating by ELISA method. Analysis performed were correlations IR-indexes with adiposity, receiver operating characteristic (ROC) curves and the adiponectin-oligomers, resolvin-E1 and chemerin tertiles.

Results: Subjects' with-obesity showed adiposopathy status, characterized by metabolic dysregulation and a subclinical inflammatory profile. They presented higher levels $(\bar{x} \pm \mathrm{SD}, \mathrm{ng} / \mathrm{mL})$ of resolvin-E1 (1227 \pm 668 versus $909 \pm 769, P=0.017)$, chemerin $(91 \pm 31$ versus $79 \pm 23, P=0.013)$ and LMW-Adiponectin (2257 \pm 797 versus $1030 \pm 1055, P=0.011$ ), whereas HMW-Adiponectin was lower ( $2470 \pm 1095$ versus $3236 \pm 1848, P=0.010$ ), compared to the without-obesity individuals. Individuals with-obesity also displayed positive correlation of IR markers ( $r$ bo from 0.163 to 0.479 ) along body fat measurements, metabolic and inflammation profiles. Moreover, a negative correlation of HMW-Adiponectin ( $r$ ho from -0.564 to -0.214 ) with body fat measurements, metabolic and inflammation profiles. IR-indexes, LMWAdiponectin and resolvin-E1/chemerin relationship showed differences between groups' with-obesity and without-obesity, but not with gender. ROC curves shown potential ability of the LMW-Adiponectin levels to differentiate IR from non-IR individuals, with AUC of 0.815, $P<0.0001$ (95\%, CI: 0.726-0.903).
\end{abstract}

Conclusion: The present study shown that LMW-Adiponectin-resolvinE1-chemerin serum unbalance establishes a specific relationship with adiposopathy in individuals with obesity, which could be a way to identify risk factors in early stages of IR.

\section{Introduction}

Obesity is characterizing by high storage and irregular distribution of white adipose tissue (WAT). It has dysmetabolic and subclinical inflammatory process with increase synthesis of adipokines and chemokines, these processes develop into an adiposopathy status (pathological function of WAT) that causes insulin resistance (IR) [1-4].

Inside of WAT, the interaction between immune cells and adipocytes favors releasing adiponectin and chemerin that stimulate,
${ }^{*}$ Correspondence to: Rosa-Elena Navarro-Hernandez, Centro Universitario de Ciencias de la Salud, Universidad de Guadalajara, Sierra Mojada No. 950, Colonia Independencia, C.P. 44340. Guadalajara, Jal, Mexico, Tel +52 331058 5309, E-mail: rosa_elena_n@hotmail.com

Key words: adiponectin oligomers, chemerin, resolvin-E1, adiposopathy, body fat distribution, insulin resistance metabolic markers, inflammatory markers

Received: February 04, 2019; Accepted: February 22, 2019; Published: February 25,2019 

in obesity

themselves or surrounded cells to further produce inflammatory mediators $[5,6]$. While, healing and pro-resolve processes are triggered by the production of lipid mediators (resolvins), through mechanisms of inflammation/resolution $[7,8]$.

For instance, while resolvin-E1 (RvE1) is generated in response to inflammation by the interaction of endothelial cells with neutrophil leukocyte, chemerin has both active and inactive effects by an autocrine/ paracrine mechanism, it plays an important role in adipocyte's differentiation [9-12]. Also, adiponectin is synthetized by WAT and suffers posttranscriptional changes, on three oligomeric forms: trimer (LMW), hexamer (MMW), and high (HMW) molecular weight. These variations display functional differences according on their levels and exert distinct biological effects and tissue-selective functions [13-15].

Although, RvE1 and chemerin are different in biochemical nature, with antagonistic properties, both shares the same receptor, CMKLR1 [16]. In obesity, the inflammatory response [17] promote a chronic subclinical inflammation and leads to the development of IR [6], it was linked with up-regulation of CMKLR1 expression which degenerates the signaling pathway when one (RvE1) or another (chemerin) ligand binds $[1,18]$.

In the context of obesity, we search establish the balance of oligomeric adiponectin, RvE1/chemerin, which could better characterize the IR setting, based on their serum levels and relationship with inflammatory markers, metabolic profile and adiposopathy status.

\section{Patients and methods}

\section{Study subjects}

In this cross-sectional study 230 individuals (63.9\% female) who had 20 to 59 years old, were eligible from general population. They were classify based on World Health Organization criteria by body mass index (BMI) in two groups as follows: study group (with-obesity $\mathrm{n}=77$ ) BMI from 30.0 to $39.9 \mathrm{~kg} / \mathrm{m}^{2}$ and comparison group (without-obesity $\mathrm{n}$ = 153) BMI from 18.5 to $29.9 \mathrm{~kg} / \mathrm{m}^{2}$.

\section{Ethics conduct}

Before the enrollment, all individuals gave their signature in a consent document after they were informed about to participate in the study. The consent form followed both, the Helsinki declaration and the institutional review boards' committees (Guadalajara University) guidelines, which has ensured appropriate ethical and conduct of biosecurity.

\section{Clinical assessments}

Physical examination and medical history were achieved from all participants, whom to answer a structured questionnaire as prerequisite to evaluate demographical and clinical variables; personal and family medical history were obtain. To enforce the quality of the groups, the questionnaire included questions about current health status, and whether they had body weight change in the last three weeks, if someone had an affirmative answer to the later these individuals were excluded from the study. The individuals who had pharmacological treatment, cardiovascular disease or previous diagnosis of metabolic diseases such as hypertension or diabetes, were also exclude.

\section{Subjects' distribution and storage of body fat and status of adiposity}

We evaluated the following measurements:
Storage and distribution of body fat: Body weight $(\mathrm{kg})$, total body fat mass and trunk fat mass [absolute $(\mathrm{kg})$ and relative (\%)], were determined by using bioelectrical impedance analysis, (TANITA BC418 segmental body composition analyzer. Tokyo, JPN) to the nearest $0.1 \mathrm{~kg}$; five (abdominal, bicipital, tricipital, subscapular and suprailiac) skinfold thickness was obtain on the right side of the body by using a Harpenden skinfold caliper (opened $80 \mathrm{~mm}$ and precision of $\pm 0.2 \mathrm{~mm}$, constant pressure: $10 \mathrm{~g} / \mathrm{mm}^{2}$; Holtain Ltd. Croswell, Crymych, Pembs., SA41 3UF, UK).

Body dimensions (cm): Height was measure to the nearest $1 \mathrm{~mm}$ by using a stadiometer (Seca GmbH \& Co. KG. Hamburg, Germany), waist circumference (WC), hip circumference (HC) [19] and coronal abdominal diameter, were measured by using an anthropometric fiberglass tape (GULICK" length $0-180 \mathrm{~cm}$ precision \pm 0.1 ; USA). At the level of the iliac crest (L4-L5) sagittal abdominal diameter was measured using a sliding-beam, abdominal caliper (precision \pm 0.1 cm, Holtain Ltd. Croswell, Crymych, Pembs, SA41 3UF, UK.) with the patient lying in a supine position in the examination table [20].

Status of adiposity: To determine obesity and adiposity indexes the following math calculations were used: $\mathrm{BMI}\left(\mathrm{kg} / \mathrm{m}^{2}\right)=$ body weight $(\mathrm{kg}) /$ height $(\mathrm{m})^{2}$. Body fat ratio $\left(\mathrm{kg} / \mathrm{m}^{2}\right)=$ total body fat mass $(\mathrm{kg}) /$ height $(\mathrm{m})^{2}$. Waist to height ratio $=\mathrm{WC}(\mathrm{cm}) /$ height $(\mathrm{cm})$ [21]. Waist-hip ratio $=$ WC $(\mathrm{cm}) / \mathrm{HC}(\mathrm{cm})$. Conicity index $=\mathrm{WC}(\mathrm{m}) / 0.109 \sqrt{ }$ (weight $(\mathrm{kg}) /$ height $(\mathrm{m})$. Total adipose area $\left(\mathrm{cm}^{2}\right)=\mathrm{WC}^{2} / 4 \pi$ Visceral area $\left(\mathrm{cm}^{2}\right)$ $=\pi(\mathrm{WC} / 2 \pi-\text { abdominal skinfold })^{2}$. Subcutaneous abdominal area $\left(\mathrm{cm}^{2}\right)=$ total adipose area - visceral area [22]. Visceral adiposity index: for females, $=(\mathrm{WC} / 36.58+(1.896 \mathrm{BMI})) 6(\mathrm{TG} / 0.81) 6(1.52 / \mathrm{HDLc})$ and males $=(\mathrm{WC} / 39.68+(1.886 \mathrm{BMI})) 6(\mathrm{TG} / 1.03) 6(1.31 / \mathrm{HDLc})[23]$. Abdominal volume index $(\mathrm{L})=\left[2\left(\mathrm{WC}^{2}+0.7(\mathrm{WC}-\mathrm{HC})^{2}\right] / 1000[24]\right.$.

All these measurements were carrying out by the same anthropometrist in duplicate following the procedures recommended by anthropometric indicators measurement guide.

\section{Metabolic and inflammatory markers}

Individuals included in the study were fasting 12 hours before blood samples were taken, allowing them to clot at room temperature, then were centrifuged at 1509 RCF (Rotanta 460R, Andreas Hettich $\mathrm{GmbH} \& \mathrm{Co}$. KG.) for 10 minutes at $20^{\circ} \mathrm{C}$. Serum was collected and stored at $-80^{\circ} \mathrm{C}$ until further analysis.

With routine enzymatic, immuno-turbidimetry and colorimetric methods we quantified the serum concentration $(\mathrm{mg} / \mathrm{dL})$ of: fasting glucose, triglycerides (TG), total cholesterol (TC), HDLc, LDLc and VLDLc (with the Friedewald formula) [25], (high, low and very low density lipoprotein cholesterol, respectively), small dense LDLc (sdLDLc), apolipoproteins A-1 (Apo A-1) and B (Apo B), and nonesterified fatty acids (NEFAs $\mathrm{mmol} / \mathrm{L}$ ). High sensitivity $C$ reactive protein (limit of detection of $0.15 \mathrm{mg} / \mathrm{L}$ ) and complement component 3 (C3), (Randox Laboratories 55 Diamond Road, Crumlin Co. Antrim, Northern Ireland UK). Erythrocyte sedimentation rate (ESR, $\mathrm{mm} / \mathrm{h}$ ) by Wintrobe method [26].

Based on the lipid profile measurements we calculate the following cholesterol ratios: non-sdLDLc $=$ LDLc - sdLDLc $(\mathrm{mg} / \mathrm{dL}), \%$ sdLDLc, sdLDLc/HDLc, TG/HDLc, TC/HDLc, LDLc/HDLc, and Apo B/ Apo A-1. Additionally, follow insulin indexes were estimating: the homeostasis model assessment (HOMA)-IR $=$ [fasting serum glucose $\mathrm{mg} / \mathrm{dL} \times($ fasting serum insulin $\mu \mathrm{IU} / \mathrm{mL}) / 405]$, Quantitative insulin sensitivity check index, QUICKI $=[1 /(\log ($ fasting serum insulin $\mu \mathrm{IU} /$ $\mathrm{mL})+\log ($ fasting glucose, $\mathrm{mg} / \mathrm{dL})]$, HOMA-adiponectin $(\mathrm{AD})=[$ fasting 
Madrigal-Ruiz PM (2019) The unbalance of adiponectin oligomers, RvE1 and chemerin levels are associate with increase of adiposopathy status and insulin resistance in obesity

glucose $(\mathrm{mmol} / \mathrm{L}) \times$ fasting serum insulin $\mu \mathrm{IU} / \mathrm{mL})] /[22.5 \times$ fasting adiponectin $(\mu \mathrm{g} / \mathrm{mL})]$, HOMA-B $=20 \times$ insulin $(\mu \mathrm{IU} / \mathrm{mL}) /[$ glucose $(\mathrm{mmol} / \mathrm{L})-3.5]$ and basal disposition index (DI), was calculate as HOMA-B/HOMA-IR $[27,28]$.

\section{Adiponectin oligomers, RvE1 and chemerin serum levels techniques}

Following the manufactures instructions of commercial the quantitative enzyme-linked immunoassay technique (ELISA) kits were determined soluble levels of insulin $(\mu \mathrm{IU} / \mathrm{mL})$, oligomers (HMW, MMW and LMW) and total adiponectin $(\mathrm{ng} / \mathrm{mL})(80$-INSHU-E01.1, 47-ADPHU-E01. ALPCO 26-G Keewaydin Drive, Salem, NH 03079, respectively), chemerin (ng/mL) (DCHM00 R\&D Systems Inc. 614 McKinley Place NE, Minneapolis, MN 55413, USA), and RvE1 ( $\mu \mathrm{g} /$ mL) (MBS286046. My BioSource, Inc. P.O. Box 153308 San Diego, CA 92195-3308 USA). The sensitivity of the assays are $0.399 \mu \mathrm{IU} / \mathrm{mL}, 0.019$ $\mathrm{ng} / \mathrm{mL}, 4.13 \mathrm{pg} / \mathrm{mL}$ and $0.1 \mu \mathrm{g} / \mathrm{mL}$, respectively.

Based on biomarkers criteria, RvE1-chemerin relationship were perform as follows: RvE1/chemerin index $=\left[1+\log _{10}(\operatorname{RvE} 1(\mathrm{ng} / \mathrm{mL}))\right.$ - $\log _{10}($ chemerin $\left.(\mathrm{ng} / \mathrm{mL}))\right]$; RvE1/chemerin ratio $=\operatorname{RvE} 1(\mathrm{ng} / \mathrm{mL}) /$ chemerin $(\mathrm{ng} / \mathrm{mL})$.

\section{Statistical analysis}

Data were analyzed with statistical software packages SPSS v24 (IBM Inc., Chicago, IL, USA) and Graph-Pad Prism v6.01 (2014 Inc. 2236 Beach Avenue Jolla, CA 92037). The normal distribution of clinical and laboratory variables was evaluated with $Z$ Kolmogorov-Smirnov test. Results were given as mean $\pm \mathrm{SD}$, minimum and maximum or percentages.

Detailed test by tertiles was perform as follows: describing the first tertile as low levels, second tertile as intermediate levels, and third tertile as high levels. The clinical and laboratory characteristics of study groups were compared with the unpaired Student's $t$-test or ANOVA one-way test and Tukey post hoc test.

Data from serum concentrations of adiponectin-oligomers, RvE1, chemerin, IR indexes, metabolic and inflammatory markers assessment, and adiposity variables were subject to Spearman correlation tests. Receiver operating characteristic (ROC) curve was generate for LMWAdiponectin levels and HOMA-AD and the area under curve (AUC) value and $95 \%$ confidence intervals $(\mathrm{CI})$ were calculated to determine the specificity and sensitivity for IR or adiposopathy status. A twotailed $P$ value $<0.05$ was consider statistically significant.

\section{Results}

Subjects with obesity showed adiposopathy status (high body dimensions and storage of body fat, and pathological distribution of adiposity)

Clinical characteristics and measurements of storage and distribution of body fat in study participants by gender are show in Table 1.

In this study, the frequency of individuals with obesity was $33 \%$, they were individuals which showed increase in body fat storage (mean $19.3 \mathrm{~kg}$ ), body dimensions, status of adiposity, and irregular abdominal fat distribution, while were similar in age with the without-obesity group. This anthropometric evaluation displayed those individuals with-obesity presented 2.02 times more quantity and $12.7 \%$ more in proportion of body fat (data no shown) compared with the without- obesity group. It is important to note that in the trunk there is more quantity of the body fat stored (Table 1).

\section{Group with-obesity present metabolic dysregulation and subclinical inflammatory profile}

Group with-obesity show a lipids profile with metabolic dysregulation, it is important to mention that also presented higher insulin and lipids indexes compared to without-obesity group (Figure 1 and Figure 2C).

When inflammation markers were taken in consideration, group with-obesity present subclinical low-grade inflammation, represented by higher levels compared with group without-obesity of $\mathrm{C}$ reactive protein $(\overline{\mathrm{x}}=2.51 \mathrm{mg} / \mathrm{L} \pm 3.26$ versus $5.65 \mathrm{mg} / \mathrm{L} \pm 4.64, P<0.0001), \mathrm{C} 3$ $\mathrm{x} \mathrm{x}=194 \mathrm{mg} / \mathrm{dL} \pm 73$ versus $251 \mathrm{mg} / \mathrm{dL} \pm 95, P<0.0001)$ and ESR $(\overline{\mathrm{x}}$ $=14.6 \mathrm{~mm} / \mathrm{h} \pm 10.0$ versus $19.5 \mathrm{~mm} / \mathrm{h} \pm 11.7, P=0.002)$, respectively.

Individuals' with-obesity presented high levels of RvE1, chemerin and adiponectin oligomers

Group with-obesity was presented higher levels of RvE1 compared with group without-obesity. Same fashion was observed with chemerin levels, and LMW-Adiponectin, whereas HMW-Adiponectin shown lower levels and RvE1-chemerin index and ratio were higher in obesity than without-obesity group (Figure 2A and B).

Unlike way was observe in without-obesity individuals when gender was acquiring in consideration, females shown higher levels than males (Figure 2D and E). Despite the fact insulin indexes were higher in the group with-obesity while in males versus females did not shown differences, with exception of QUIKI index (Figure 2C and F).

Resolvin E1, chemerin and adiponectin oligomers levels unbalance were associated with adiposopathy status

In whole group RvE1, chemerin and LMW-Adiponectin levels and HOMA-AD displayed positive correlations along body fat measurements, metabolic profile and inflammatory markers, even though HMW-Adiponectin correlated negatively, with the following pattern (Table 2)

a) We observe correlations of levels of RvE1, chemerin and LMWAdiponectin (positively, rho from 17.1 to 47.9) and HMWAdiponectin (negatively, rho from -56.4 to -21.4) with IR indexes, trunk fat mass proportion, total adipose area and abdominal volume index, while HDLc and apolipoprotein A-1 correlate positively.

b) Chemerin and LMW-Adiponectin levels displayed correlations in similar way along body fat measurements.

c) The body dimensions, metabolic and inflammatory markers alternately were correlate with levels of RvE1 or chemerin and HMW-Adiponectin, it is when RvE1 correlated the chemerin and HMW-Adiponectin levels no shown correlation.

d) We note that RvE1, chemerin and HMW-Adiponectin each correlate with a different inflammation marker.

e) LMW-Adiponectin and HOMA-AD displayed positive correlations along body fat measurements and inflammatory markers, but not with metabolic profile.

Additionally, we performed multiple regression analysis, where we normalized (ln-transform) data and found that waist and hip circumferences, sagittal abdominal diameter and conicity index predict $14.5 \%$ of the variation in chemerin levels (Table 3 ). The model adjusted 
Madrigal-Ruiz PM (2019) The unbalance of adiponectin oligomers, RvE1 and chemerin levels are associate with increase of adiposopathy status and insulin resistance in obesity

Table 1. Clinical characteristics, and storage measurements and body fat distribution of study groups

\begin{tabular}{|c|c|c|c|c|}
\hline \multirow{3}{*}{$\begin{array}{l}\text { Gender (n) } \\
\left.\text { Obesity [BMI }\left(\mathrm{kg} / \mathrm{m}^{2}\right)\right]\end{array}$} & \multicolumn{4}{|c|}{ Study groups } \\
\hline & \multicolumn{2}{|c|}{ Male (83) } & \multicolumn{2}{|c|}{ Female (147) } \\
\hline & $\begin{array}{l}\text { Without }[19.6-29.4] \\
n=61\end{array}$ & $\begin{array}{c}\text { With }[30.4-38.1] \\
n=22\end{array}$ & $\begin{array}{l}\text { Without }[18.7-29.9] \\
\mathrm{n}=92\end{array}$ & $\begin{array}{c}\text { With }[30.1-39.0] \\
n=55\end{array}$ \\
\hline \multicolumn{5}{|l|}{ Measurements } \\
\hline Age (years) & $32 \pm 12$ & $36 \pm 13$ & $33 \pm 13$ & $44 \pm 9$ \\
\hline \multicolumn{5}{|l|}{ Storage of body fat } \\
\hline Body weight $(\mathrm{kg})^{*}$ & $76.4 \pm 11.0$ & $102.8 \pm 22.4$ & $62.1 \pm 10.3$ & $90.1 \pm 12.8$ \\
\hline Total body fat mass $(\%)^{*}$ & $21.0 \pm 5.9$ & $33.4 \pm 6.9$ & $31.9 \pm 6.6$ & $43.4 \pm 4.4$ \\
\hline Total body fat mass $(\mathrm{kg})^{*}$ & $16.2 \pm 5.3$ & $35.6 \pm 17.2$ & $20.5 \pm 7.2$ & $39.4 \pm 8.2$ \\
\hline 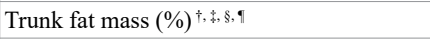 & $26.2 \pm 11.7$ & $34.8 \pm 7.5$ & $31.1 \pm 10.6$ & $40.2 \pm 9.3$ \\
\hline Trunk fat mass $(\mathrm{kg}) \stackrel{ \pm, \S, q, * *}{ }$ & $9.5 \pm 3.5$ & $19.3 \pm 7.1$ & $9.7 \pm 4.3$ & $18.7 \pm 4.7$ \\
\hline \multicolumn{5}{|l|}{ Body dimensions $(\mathrm{cm})$} \\
\hline Height $\uparrow, \downarrow, q, * *$ & $173 \pm 7$ & $170 \pm 5$ & $159 \pm 7$ & $159 \pm 5$ \\
\hline Waist circumference ${ }^{\dagger, 8, q, * *, \bar{\dagger}}$ & $92.0 \pm 9.3$ & $113.0 \pm 15.1$ & $86.8 \pm 11.4$ & $112.3 \pm 11.3$ \\
\hline Hip circumference $\$, q, * *, \dagger$ & $98.6 \pm 6.0$ & $114.4 \pm 12.2$ & $99.5 \pm 7.0$ & $118.4 \pm 11.3$ \\
\hline Coronal abdominal diameter $\downarrow, \S, \uparrow, * *, \dagger \dagger$ & $38.1 \pm 7.0$ & $48.1 \pm 12.3$ & $34.4 \pm 6.4$ & $42.9 \pm 10.0$ \\
\hline Sagittal abdominal diameter $\uparrow, \S, q, * *, \dagger \dagger$ & $19.4 \pm 2.5$ & $25.3 \pm 3.6$ & $18.0 \pm 2.3$ & $24.4 \pm 2.8$ \\
\hline \multicolumn{5}{|l|}{ Status of adiposity } \\
\hline Body fat ratio $\left(\mathrm{kg} / \mathrm{m}^{2}\right)^{*}$ & $5.4 \pm 1.8$ & $12.0 \pm 5.0$ & $8.0 \pm 2.6$ & $15.4 \pm 2.9$ \\
\hline Waist to height ratio $\$, q, * *, \uparrow \dagger$ & $0.53 \pm 0.05$ & $0.66 \pm 0.07$ & $0.54 \pm 0.07$ & $0.70 \pm 0.07$ \\
\hline Waist-hip ratio ${ }^{\dagger, * *, \dagger \dagger}$ & $0.93 \pm 0.06$ & $0.98 \pm 0.05$ & $0.87 \pm 0.08$ & $0.95 \pm 0.11$ \\
\hline Conicity index $\uparrow, * *, \dagger$ & $1.27 \pm 0.08$ & $1.34 \pm 0.07$ & $1.27 \pm 0.11$ & $1.37 \pm 0.09$ \\
\hline Total adipose area $\left(\mathrm{cm}^{2}\right)^{\$, 9, * *, \dagger \dagger}$ & $680 \pm 137$ & $1035 \pm 297$ & $610 \pm 155$ & $1020 \pm 211$ \\
\hline Visceral area $\left(\mathrm{cm}^{2}\right)$ & $366 \pm 346$ & $514 \pm 471$ & $322 \pm 323$ & $459 \pm 458$ \\
\hline Subcutaneous abdominal area $\left(\mathrm{cm}^{2}\right)^{\S, \uparrow, * *, \dagger \dagger}$ & $529 \pm 174$ & $756 \pm 360$ & $456 \pm 190$ & $840 \pm 299$ \\
\hline Visceral adiposity index ${ }^{\dagger, * *, \dagger \dagger}$ & $4.0 \pm 2.7$ & $4.3 \pm 1.5$ & $2.5 \pm 1.9$ & $3.8 \pm 2.6$ \\
\hline Abdominal volume index $(\mathrm{L})^{\S, q, * *, \mathrm{i} \dagger}$ & $17.1 \pm 3.4$ & $26.0 \pm 7.4$ & $15.5 \pm 3.7$ & $25.7 \pm 5.2$ \\
\hline \multicolumn{5}{|c|}{ Body fat distribution [Skinfold thicknesses (mm)] } \\
\hline Abdominal $\$, \uparrow, * *, \dagger \dagger$ & $20.3 \pm 7.1$ & $27.7 \pm 7.1$ & $20.5 \pm 6.1$ & $24.3 \pm 7.8$ \\
\hline Bicipital* & $6.5 \pm 2.8$ & $13.3 \pm 6.9$ & $10.1 \pm 4.5$ & $18.4 \pm 6.5$ \\
\hline Tricipital $\uparrow, \downarrow, \S, q, \dagger \dagger$ & $13.0 \pm 4.4$ & $22.3 \pm 8.0$ & $20.0 \pm 5.1$ & $26.2 \pm 6.0$ \\
\hline Subscapular ${ }^{\S, q}, * *, \dagger$ & $17.9 \pm 5.3$ & $26.9 \pm 7.5$ & $18.1 \pm 6.2$ & $29.3 \pm 7.6$ \\
\hline Suprailiac $\$, \uparrow, * *, \dagger$ & $15.6 \pm 6.5$ & $27.9 \pm 9.1$ & $17.8 \pm 6.4$ & $27.4 \pm 8.0$ \\
\hline
\end{tabular}

(Data are show in $\overline{\mathrm{x}} \pm \mathrm{SD}$. Differences between groups by One-way ANOVA and Tuckey post Hoc, $P<0.05$, *: Differences between all groups

${ }^{\dagger}$ : Male without obesity versus Female without obesity, ${ }^{*}$ : Male with obesity versus Female with obesity, ${ }^{\S}$ : Male without obesity versus Male with obesity, ${ }^{\uparrow}$ : Male without obesity versus Female with obesity, ${ }^{* *}$ : Female without obesity versus Male with obesity, ${ }^{\dagger}$ : Female without obesity versus Female with obesity)

Table 2. Adiponectin oligomers, resolvin E1 and chemerin correlations

\begin{tabular}{|c|c|c|c|c|c|c|c|c|c|c|}
\hline \multirow[b]{2}{*}{ Measurements } & \multicolumn{10}{|c|}{ Rho Correlation coefficient of circulating levels } \\
\hline & $\begin{array}{l}\text { RvE1 } \\
\text { (ng/mL) }\end{array}$ & $\boldsymbol{P}$ & $\begin{array}{l}\text { Chemerin } \\
\text { (ng/mL) }\end{array}$ & $\boldsymbol{P}$ & $\begin{array}{l}\text { HMW-Adiponectin } \\
\text { (ng/mL) }\end{array}$ & $P$ & $\begin{array}{l}\text { LMW-Adiponectin } \\
\text { (ng/mL) }\end{array}$ & $\boldsymbol{P}$ & HOMA-AD & $\boldsymbol{P}$ \\
\hline \multicolumn{11}{|l|}{ Storage of body fat (\%) } \\
\hline Total body fat mass & 0.221 & 0.011 & 0.385 & 0.000 & 0.005 & NS & 0.260 & 0.009 & 0.385 & 0.000 \\
\hline Trunk fat mass & 0.172 & 0.049 & 0.282 & 0.000 & -0.102 & NS & 0.244 & 0.015 & 0.475 & 0.000 \\
\hline \multicolumn{11}{|l|}{ Body dimensions $(\mathrm{cm})$} \\
\hline Waist circumference & 0.126 & NS & 0.188 & 0.021 & -0.199 & 0.048 & 0.290 & 0.004 & 0.508 & 0.000 \\
\hline Hip circumference & 0.093 & NS & 0.216 & 0.008 & -0.126 & NS & 0.323 & 0.001 & 0.496 & 0.000 \\
\hline Sagittal abdominal diameter & 0.053 & NS & 0.157 & NS & -0.235 & 0.021 & 0.304 & 0.003 & 0.532 & 0.000 \\
\hline \multicolumn{11}{|l|}{ Status of adiposity } \\
\hline BMI $\left(\mathrm{kg} / \mathrm{m}^{2}\right)$ & 0.107 & NS & 0.153 & NS & -0.222 & 0.026 & 0.335 & 0.001 & 0.536 & 0.000 \\
\hline Body fat ratio $\left(\mathrm{kg} / \mathrm{m}^{2}\right)$ & 0.190 & 0.029 & 0.315 & 0.000 & -0.070 & NS & 0.297 & 0.003 & 0.466 & 0.000 \\
\hline Waist to height ratio & 0.215 & 0.014 & 0.288 & 0.000 & -0.106 & NS & 0.299 & 0.003 & 0.465 & 0.000 \\
\hline Conicity index & 0.197 & 0.025 & 0.307 & 0.000 & -0.070 & NS & 0.210 & 0.038 & 0.294 & 0.003 \\
\hline Total adipose area $\left(\mathrm{cm}^{2}\right)$ & 0.126 & NS & 0.188 & 0.021 & -0.199 & 0.048 & 0.290 & 0.004 & 0.508 & 0.000 \\
\hline Subcutaneous abdominal area $\left(\mathrm{cm}^{2}\right)$ & 0.147 & NS & 0.204 & 0.031 & -0.065 & NS & 0.240 & 0.047 & 0.298 & 0.011 \\
\hline Visceral adiposity index & 0.070 & NS & 0.111 & NS & -0.332 & 0.001 & 0.105 & NS & 0.411 & 0.000 \\
\hline Abdominal volume index & 0.127 & NS & 0.192 & 0.018 & -0.198 & 0.048 & 0.289 & 0.004 & 0.509 & 0.000 \\
\hline \multicolumn{11}{|l|}{ Metabolic markers $(\mathrm{mg} / \mathrm{dL})$} \\
\hline Triglycerides & 0.147 & NS & 0.204 & 0.012 & -0.252 & 0.011 & 0.152 & NS & 0.369 & 0.000 \\
\hline HDLc & 0.112 & NS & 0.174 & 0.032 & 0.161 & NS & 0.038 & NS & -0.138 & NS \\
\hline
\end{tabular}


Madrigal-Ruiz PM (2019) The unbalance of adiponectin oligomers, RvE1 and chemerin levels are associate with increase of adiposopathy status and insulin resistance in obesity

\begin{tabular}{|c|c|c|c|c|c|c|c|c|c|c|}
\hline \multirow[b]{2}{*}{ Measurements } & \multicolumn{10}{|c|}{ Rho Correlation coefficient of circulating levels } \\
\hline & $\begin{array}{l}\text { RvE1 } \\
\text { (ng/mL) }\end{array}$ & $\boldsymbol{P}$ & $\begin{array}{l}\text { Chemerin } \\
(\mathrm{ng} / \mathrm{mL})\end{array}$ & $\boldsymbol{P}$ & $\begin{array}{l}\text { HMW-Adiponectin } \\
\text { (ng/mL) }\end{array}$ & $\boldsymbol{P}$ & $\begin{array}{l}\text { LMW-Adiponectin } \\
\text { (ng/mL) }\end{array}$ & $\boldsymbol{P}$ & HOMA-AD & $\boldsymbol{P}$ \\
\hline LDLc & 0.264 & 0.002 & 0.130 & NS & -0.024 & NS & 0.015 & NS & 0.071 & NS \\
\hline VLDLc & 0.147 & NS & 0.204 & 0.012 & -0.252 & 0.011 & 0.152 & NS & 0.369 & 0.000 \\
\hline sdLDLc & -0.020 & NS & 0.441 & 0.035 & -0.115 & NS & 0.017 & NS & 0.218 & NS \\
\hline Apolipoprotein A-1 & -0.112 & NS & 0.093 & NS & 0.564 & 0.000 & 0.067 & NS & -0.369 & 0.027 \\
\hline NEFAs (mmol/L) & 0.324 & 0.001 & 0.302 & 0.002 & 0.074 & NS & -0.108 & NS & 0.126 & NS \\
\hline Insulin (OIU/mL) & 0.171 & 0.050 & 0.054 & NS & -0.379 & 0.000 & 0.269 & 0.007 & - & - \\
\hline \multicolumn{11}{|l|}{ Cholesterol ratios } \\
\hline LDLc/HDLc & 0.136 & NS & 0.029 & NS & -0.159 & NS & -0.031 & NS & 0.176 & NS \\
\hline TG/HDLc & 0.056 & NS & 0.099 & NS & -0.335 & 0.001 & 0.111 & NS & 0.406 & 0.000 \\
\hline sdLDLc/HDLc & 0.097 & NS & 0.524 & 0.010 & -0.117 & NS & -0.039 & NS & 0.272 & NS \\
\hline \multicolumn{11}{|l|}{ Inflammation markers } \\
\hline $\mathrm{C}$ reactive protein $(\mathrm{mg} / \mathrm{L})$ & 0.167 & NS & 0.257 & 0.002 & -0.122 & NS & 0.187 & NS & 0.348 & 0.000 \\
\hline $\mathrm{C} 3(\mathrm{mg} / \mathrm{dL})$ & 0.133 & NS & -0.056 & NS & -0.329 & 0.005 & -0.094 & NS & 0.517 & 0.000 \\
\hline $\operatorname{ESR}(\mathrm{mm} / \mathrm{h})$ & 0.106 & NS & 0.311 & 0.000 & 0.048 & NS & -0.068 & NS & 0.149 & NS \\
\hline \multicolumn{11}{|l|}{ Insulin resistance indexes } \\
\hline HOMA-IR & 0.185 & 0.034 & 0.043 & NS & -0.364 & 0.000 & 0.305 & 0.002 & - & - \\
\hline QUICKI & -0.185 & 0.034 & -0.043 & NS & 0.364 & 0.000 & -0.305 & 0.002 & - & - \\
\hline HOMA-B & 0.114 & NS & 0.115 & NS & -0.354 & 0.000 & 0.032 & NS & - & - \\
\hline DI & 0.110 & NS & 0.155 & NS & -0.352 & 0.000 & 0.022 & NS & - & - \\
\hline
\end{tabular}

(Rho Spearman's correlations in bold numbers were consider significant. $(\mathrm{n}=230)$. NS: non-significant; HMW and LMW: high and low molecular weight adiponectin; BMI: body mass index; HDLc, LDLc y VLDLc (lipoproteins of high, low and very low density cholesterol, respectively); NEFAs: nonesterified fatty acids; sdLDLc: small dense LDLc; ESR: erythrocyte sedimentation rate; HOMA: homeostasis model assessment; IR: Insulin resistance; B: beta cell function; QUICKI: quantitative insulin sensitivity check index; DI: basal disposition index)
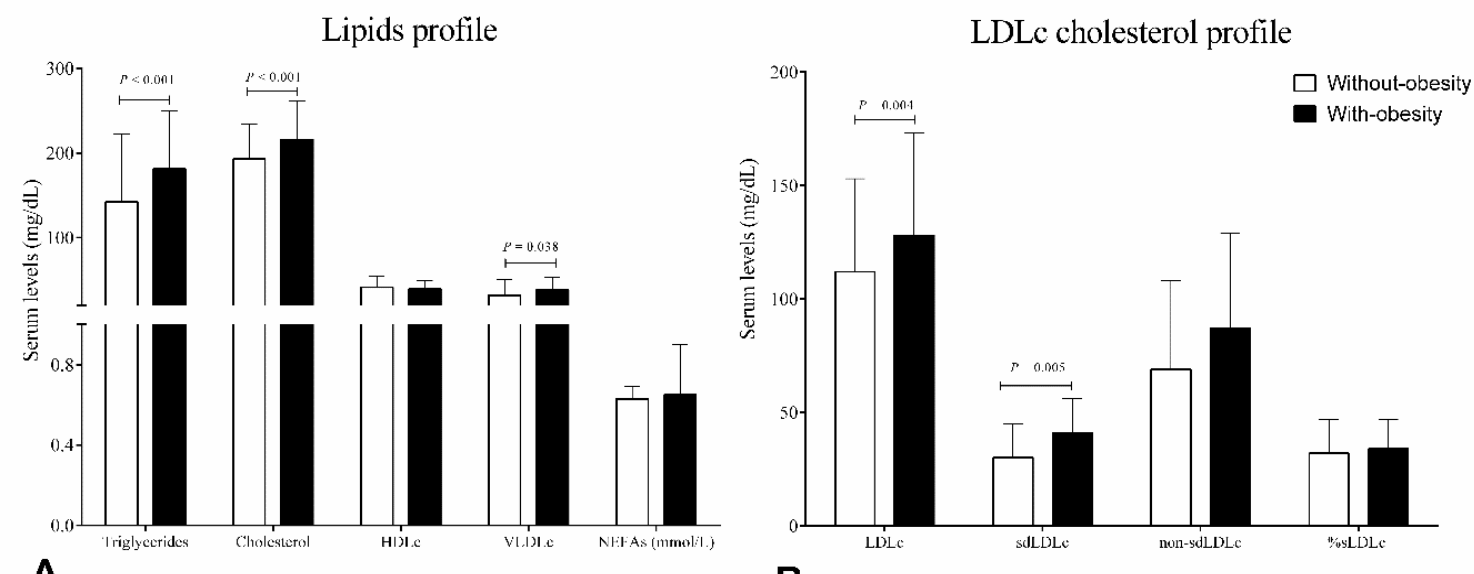

A

B
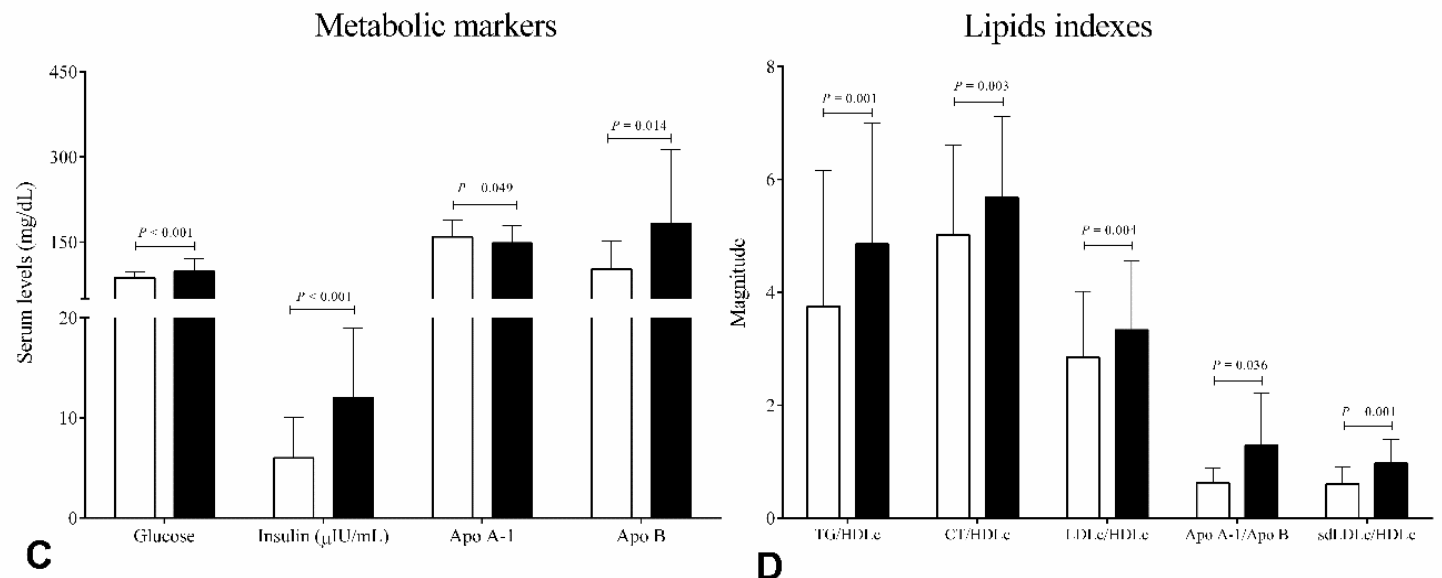

Figure 1. Metabolic markers and lipid profile. A. Lipids profile, B. LDL cholesterol profile, C. Metabolic markers, D. Lipids indexes. HDLc, LDLc and VLDLc (lipoproteins of high, low and very low-density cholesterol, respectively); sdLDLc: small dense LDLc; NEFAs: Non-esterified fatty acids. Data are shown in $\bar{x} \pm$ SD. Difference of group with-obesity [n=77, BMI: $\left.34.2(30.1-39.0) \mathrm{kg} / \mathrm{m}^{2}\right]$ versus without-obesity group [n= 153 BMI: $\left.24.8(18.7-29.9) \mathrm{kg} / \mathrm{m}^{2}\right]$. Unpaired Student's $t$ test 

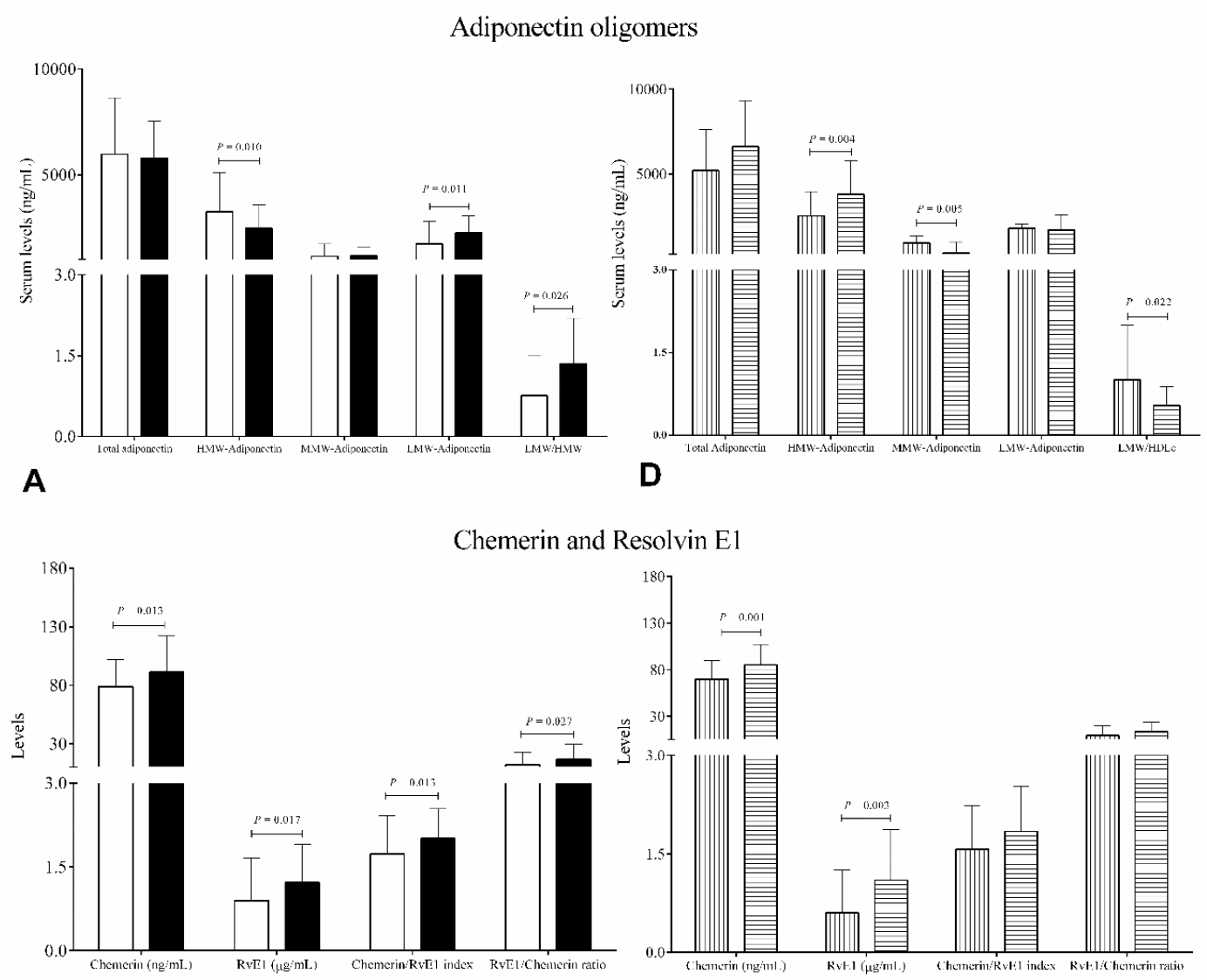

B

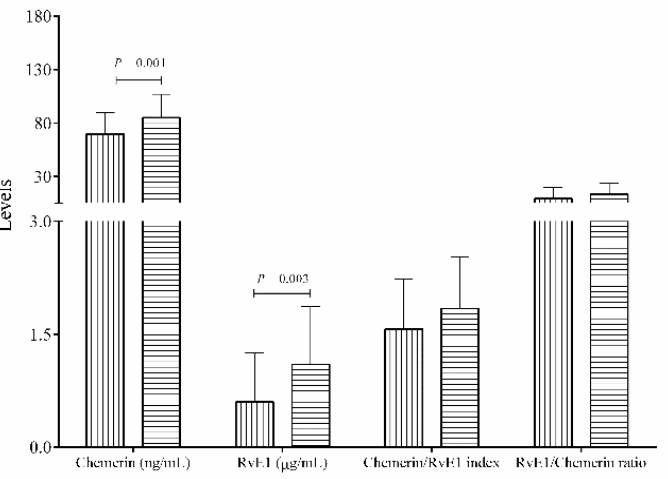

E

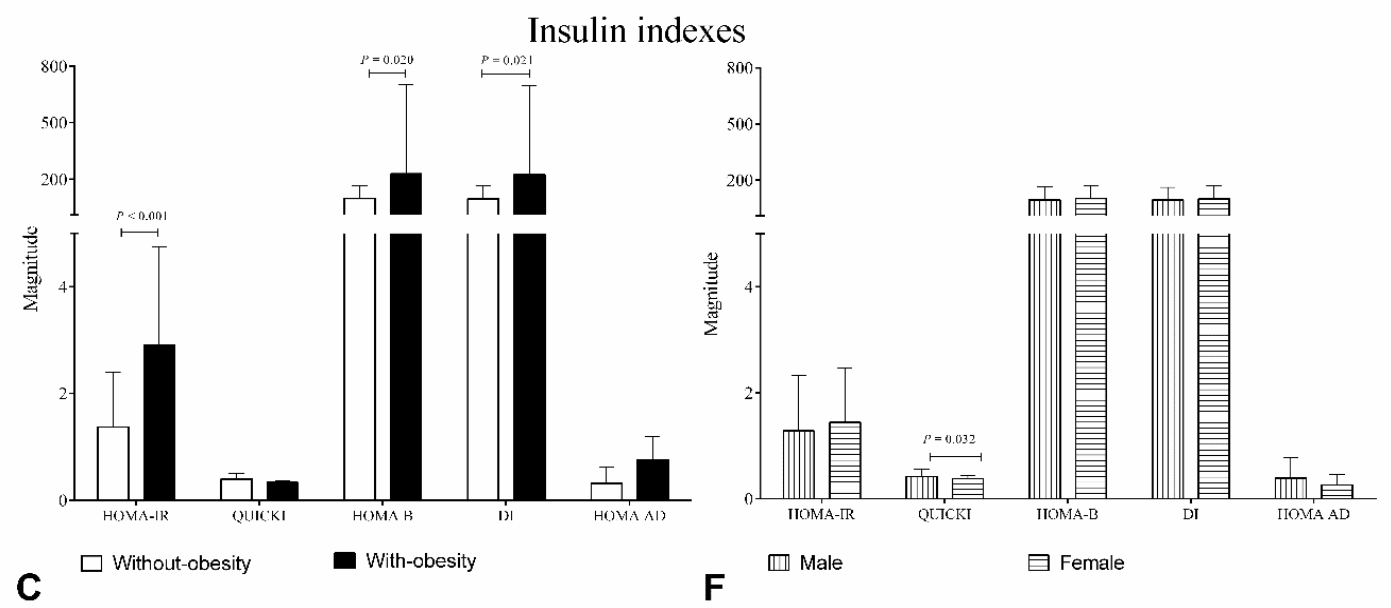

Figure 2. Serum levels of adiponectin oligomers, RvE1 and chemerin in study groups.A., B. and C. whole group, difference of group with-obesity [n=77, BMI: 34.2 (30.1 - 39.0) kg/m²] versus without-obesity group [n=153, BMI: $\left.24.8(18.7-29.9) \mathrm{kg} / \mathrm{m}^{2}\right]$. D, E and F without-obesity group, difference of Males [n=61] versus Females [n=55]. Data are show in $\overline{\mathrm{x}} \pm \mathrm{SD}$. Unpaired Student's t test

by BMI as covariable is ln chemerin $=$ [waist circumference $(-0.020)+$ hip circumference $(0.007)+$ conicity index $(1.921)+$ sagittal abdominal diameter $(0.038)+2.265]$.

Raise in the RvE1, chemerin and adiponectin oligomers unbalance are parallel to IR factors

A detailed data analysis by tertiles distribution in whole group shown that the high levels of RvE1 and chemerin were associated with high storage of body fat mass, while only high chemerin levels were associated with high body dimensions, status of adiposity, ESR and sdLDLc (Table 4).

On the other hand, higher levels of LMW-Adiponectin were associated with the increment of body fat storage, adiposity indexes, insulin levels and HOMA-IR. In the opposite, the higher levels of HMWAdiponectin were associated with reduced content of adiposity, lipids (triglycerides, VLDLc and cholesterol indexes), insulin and HOMA-IR 
Madrigal-Ruiz PM (2019) The unbalance of adiponectin oligomers, RvE1 and chemerin levels are associate with increase of adiposopathy status and insulin resistance in obesity

Table 3. Multiple regressions between chemerin serum levels and adiposopathy status (Model was calculated after adjustment for BMI. Chemerin levels were transformed to natural logarithm for normality and was regressed on age and gender, which were presented as continuous variables, whereas BMI was categorized at two levels, namely, with-obesity and withoutobesity)

\begin{tabular}{|c|c|c|}
\hline & Model natural logarithm of chemerin serum levels & \\
\hline Total $R^{2}$ & 0.145 & \\
\hline & $\beta$-Coefficient $(95 \% \mathrm{CI})$ & \\
\hline Constant & $2.265(1.374-3.184)$ & $<0.001$ \\
\hline Waist circumference $(\mathrm{cm})$ & $-0.020(-0.033--0.007)$ & 0.003 \\
\hline Hip circumference $(\mathrm{cm})$ & $0.007(-0.001-0.015)$ & 0.071 \\
\hline Conicity index & $1.921(1.054-2.788)$ & $<0.001$ \\
\hline
\end{tabular}

Table 4. Resolvin E1 and Chemerin levels associations

\begin{tabular}{|c|c|c|c|c|c|}
\hline \multirow[b]{2}{*}{$\begin{array}{l}\text { RvE1 (ng/mL) } \\
\bar{x}(\min \square \square \max )\end{array}$} & \multicolumn{3}{|c|}{ Distribution levels by tertile group } & \multirow[b]{2}{*}{$* \boldsymbol{P}$} & \multirow[b]{2}{*}{${ }^{\dagger} \boldsymbol{P}$} \\
\hline & $\begin{array}{c}\text { Low } \\
93(5-323)\end{array}$ & $\begin{array}{c}\text { Intermediate } \\
1121(324-1450)\end{array}$ & $\begin{array}{c}\text { High } \\
1816(1451-2995)\end{array}$ & & \\
\hline Total body fat mass $(\%)$ & $28.8 \pm 9.6$ & $33.6 \pm 8.8$ & $34.1 \pm 9.2$ & 0.021 & NS \\
\hline Conicity index & $1.28 \pm 0.09$ & $1.33 \pm 0.08$ & $1.33 \pm 0.11$ & 0.044 & NS \\
\hline LDLc (mg/dL) & $111 \pm 42$ & $134 \pm 46$ & $134 \pm 41$ & 0.022 & NS \\
\hline \multirow[t]{2}{*}{ NEFAs (mmol/L) } & $0.48 \pm 0.21$ & $0.77 \pm 0.83$ & $0.69 \pm 0.22$ & 0.041 & NS \\
\hline & \multicolumn{3}{|c|}{ Distribution levels by tertile group } & & \\
\hline $\begin{array}{l}\text { Chemerin levels (ng/mL) } \\
\bar{x}(\min \square \square \max )\end{array}$ & $\begin{array}{c}\text { Low } \\
57(33-68)\end{array}$ & $\begin{array}{c}\text { Intermediate } \\
80(69-91)\end{array}$ & $\begin{array}{c}\text { High } \\
115(92-196)\end{array}$ & $* \boldsymbol{P}$ & ${ }^{\dagger} \boldsymbol{P}$ \\
\hline BMI $\left(\mathrm{kg} / \mathrm{m}^{2}\right)$ & $29.4 \pm 6.3$ & $27.6 \pm 5.6$ & $31.2 \pm 6.4$ & NS & 0.008 \\
\hline \multicolumn{6}{|l|}{ Storage of body fat } \\
\hline Total body fat mass (\%) & $29.9 \pm 10.1$ & $31.7 \pm 8.7$ & $38.3 \pm 7.6$ & 0.001 & 0.001 \\
\hline Total body fat mass (kg) & $25.6 \pm 15.0$ & $24.4 \pm 10.4$ & $31.7 \pm 12.0$ & 0.041 & 0.010 \\
\hline Trunk fat mass (\%) & $29.7 \pm 9.6$ & $29.9 \pm 8.7$ & $34.8 \pm 9.1$ & 0.029 & $\mathbf{0 . 0 3 8}$ \\
\hline \multicolumn{6}{|l|}{ Body dimensions } \\
\hline Waist circumference $(\mathrm{cm})$ & $98.7 \pm 15.5$ & $96.1 \pm 14.1$ & $104.5 \pm 16.9$ & NS & 0.021 \\
\hline Hip circumference $(\mathrm{cm})$ & $104.7 \pm 1.8$ & $104.0 \pm 10.5$ & $110.7 \pm 14.3$ & 0.043 & 0.019 \\
\hline Sagittal abdominal diameter $(\mathrm{cm})$ & $21.1 \pm 3.7$ & $20.2 \pm 3.6$ & $22.5 \pm 4.3$ & NS & 0.014 \\
\hline \multicolumn{6}{|l|}{ Status of adiposity } \\
\hline Body fat ratio $\left(\mathrm{kg} / \mathrm{m}^{2}\right)$ & $9.2 \pm 5.0$ & $9.1 \pm 3.9$ & $12.3 \pm 4.4$ & 0.002 & 0.001 \\
\hline Waist to height ratio & $0.59 \pm 0.09$ & $0.58 \pm 0.08$ & $0.64 \pm 0.13$ & NS & 0.036 \\
\hline Conicity index & $1.29 \pm 0.08$ & $1.31 \pm 0.10$ & $1.35 \pm 0.10$ & 0.005 & NS \\
\hline Total adipose area $\left(\mathrm{cm}^{2}\right)$ & $795 \pm 64$ & $751 \pm 15$ & $893 \pm 288$ & NS & 0.019 \\
\hline Abdominal volume index & $20.0 \pm 6.6$ & $18.9 \pm 5.3$ & $22.5 \pm 7.2$ & NS & 0.016 \\
\hline \multicolumn{6}{|l|}{ Biomarkers } \\
\hline $\operatorname{sdLDLc}(\mathrm{mg} / \mathrm{dL})$ & $40 \pm 9$ & $38 \pm 11$ & $49 \pm 8$ & NS & 0.046 \\
\hline $\operatorname{ESR}(\mathrm{mm} / \mathrm{h})$ & $14 \pm 9$ & $15 \pm 10$ & $22 \pm 12$ & 0.001 & 0.005 \\
\hline
\end{tabular}

Data are show in $\overline{\mathrm{x}} \pm$ SD. ANOVA, Tukey post-hoc tertiles groups differences in bold numbers: *low versus high, ${ }^{\dagger}$ intermediate versus high. Difference of low versus intermediate tertiles in follows measurements: total fat mass \% $(P=0.039)$, NEFAs $(P=0.049)$, LDLc $(P=0.032)$. LDLc: Low-density lipoprotein cholesterol; NEFAs: non-esterified fatty acids; BMI: body mass index; sdLDLc: small dense LDLc; ESR: Erythrocyte sedimentation rate

(Table 5) while Apo A-1 was increased. IR was evaluated by surrogate indexes, we used the QUICKI and additionally to estimate beta cell function we used HOMA-B and measure of secretory capacity of $\beta$-cell compensate for IR as basal disposition index (DI). Further strengthen these results of IR, the HOMA-AD index was assessed (Figure 2C). It has showed differences between individuals with-obesity and withoutobesity, but not when compared males with females (Figure 2F).

LMW-Adiponectin and HOMA-AD associations show signs of specific shape of IR and adiposopathy status in individuals with obesity

In parallel way, we shown the correlation of the LMW-Adiponectin levels with the IR indexes (Figure 3A and C) and HOMA-AD with storage of body fat (Figure $3 \mathrm{E}$ ). In addition, we carried out the construction of ROC curves to evaluate the performance of the LMWAdiponectin levels within IR, and their potential ability to differentiate IR from non-IR individuals (Figure $3 \mathrm{~B}$ and $\mathrm{D}$ ).
These analyzes showed the values of AUC with IR discrimination. The result obtained in whole sample when LMW-Adiponectin levels positively correlate with HOMA-IR and negatively with QUICKI index (Figure 3A), the AUC was of $0.815, P<0.0001$ (Figure 3B). In addition, ROC curve analysis showed (95\%CI, $0.726-0.903)$. While HOMA-AD positively correlate with adiposopathy status, the AUC for obesity discrimination was $0.801 P<0.0001$ (95\%CI, $0.717-$ 0.886) (Figure 3F).

Interestingly, in obesity group AUC for LMW-Adiponectin levels was $0.781, P=0.005$ (95\% CI, $0.619-0.943$ ), (Figure 3D) and an inverse correlation were observed, LMW-Adiponectin positively correlate with HOMA-IR and DI and negatively with QUICKI index (Figure 3C).

\section{Discussion}

Two main observations emerge from the current study. First, RvE1 and chemerin are both present in individuals with obesity, with such high levels a high lipid and inflammatory profiles, were noted and 
Madrigal-Ruiz PM (2019) The unbalance of adiponectin oligomers, RvE1 and chemerin levels are associate with increase of adiposopathy status and insulin resistance in obesity

Table 5. Adiponectin oligomers levels associations

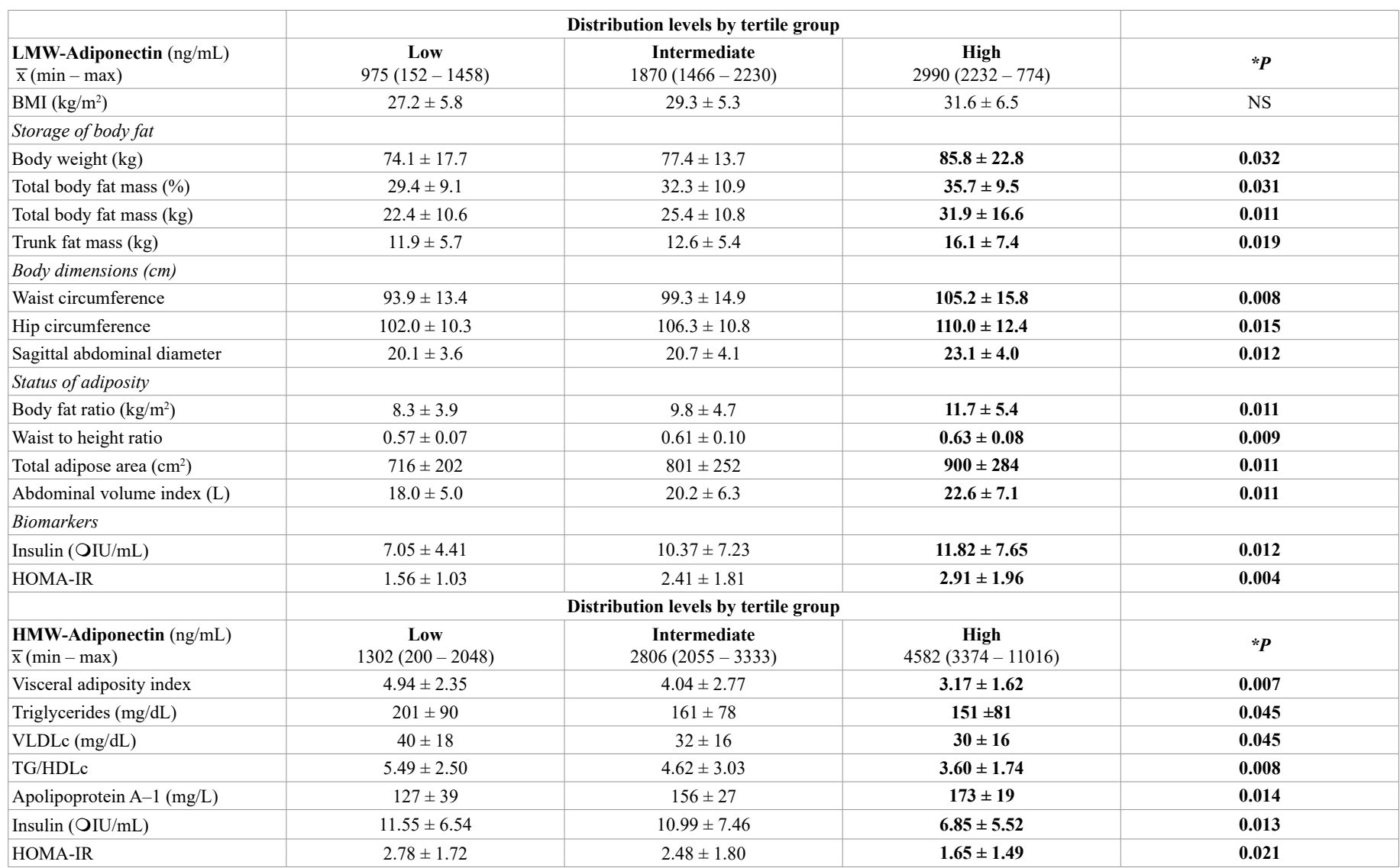

Data are show in $\overline{\mathrm{x}} \pm$ SD. ANOVA, Tukey post-hoc. Tertiles groups differences in bold numbers: *low versus high. HMW: high molecular weight; LMW: low molecular weight; BMI: body mass index; HOMA-IR; homeostasis model assessment-insulin resistance; HDLc, LDLc y VLDLc (lipoproteins of high, low and very low-density cholesterol, respectively); TG triglycerides

associated with their adiposopathy status. Secondly, the amount of LMW-Adiponectin was able to differentiate individuals with IR from non-IR individuals, beside of correlations of HOMA-AD index in adiposity setting.

It is imperative to recognize that this study was design on bases of three conceptual points, labeled together as obesity-adiposopathy status, with unbalance of: 1) adiposity setting, 2) metabolic profile and 3) biomarkers of inflammation. On which clinical records were match with circulating levels of molecules characterized as immuno-metabolic regulators in obesity such as RvE1, chemerin and oligomeric complexes of adiponectin, with which was set of breakpoints for tertiles according to the normal distribution.

This is very important to take in consideration since the concept of low-grade inflammation present in obesity has been associated with chemerin, (known with pro-inflammatory properties). Moreover, at the same time, what has not expected from this study, the RvE1, (a lipid mediator known to present pro-resolutive and antiinflammatory properties), was also present on high circulating serum levels in individuals with obesity. At this point it is essential to recall that the biological action of RvE1 and chemerin is through bind to the same receptor, the CMKLR1 [9]. Such receptor has been reported to play a crucial role with other comorbidities of obesity such as atherosclerosis [16].

One relevant result and not previously reported was the quantitative ratio of RvE1 and chemerin, and their positive correlations with body fat measurements, metabolic profile and inflammatory markers in obesity. On this setting, the present study proposes the $R v E 1 /$ chemerin index and $R v E 1 /$ chemerin ratio, as early signs of adiposopathy status in obesity.

Our proposals are based on two observations: first, earlier in the disease, the common denominator is the metabolic dysregulation and inflammatory process along the subclinical manifestations in obesity such event occurs early in the adipose tissue, with pathological adipogenesis and recruitment of circulating monocytes enhanced by polarization of M1 macrophages in tissue. All of which is identified as subclinical low-grade inflammation $[8,29,30]$.

Secondly, late in the disease, a characteristic dyslipidemia and metabolic dysregulation, was observe. Such phenomenon was with subclinical inflammation along with high IR-indexes and RvE1, chemerin and LMW-Adiponectin and low HMW-Adiponectin levels.

On the context of obesity development, all results of this study can be explained because the adipose tissue becomes permanently dysfunctional, in the producing inflammatory adipokines, both have critical role in the develop of metabolic complications associated with obesity $[31,32]$.

However, the underlying mechanisms of chronic inflammation unresolved in the development of obesity, has not been completely defined, in this scenario the evidence found shows a complex biological interrelationship between inflammatory immune response and metabolism of glucose and lipids [30]. 


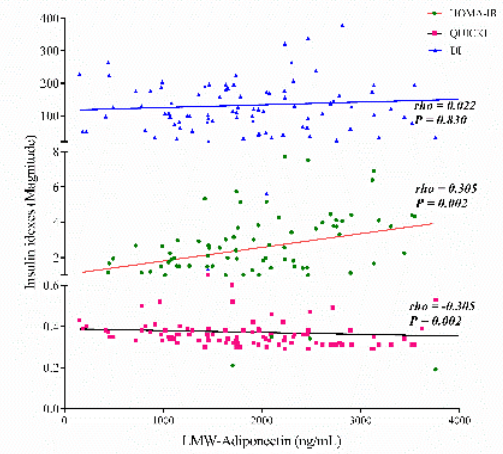

A

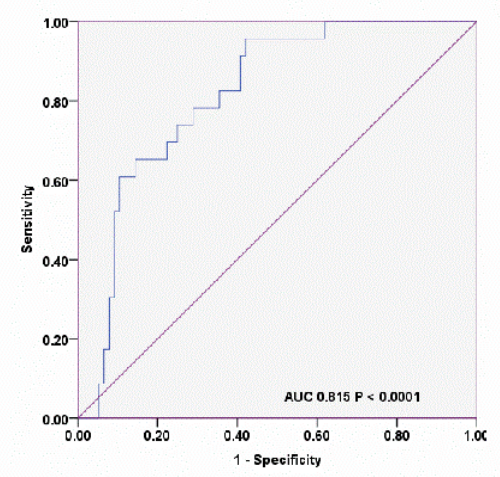

B

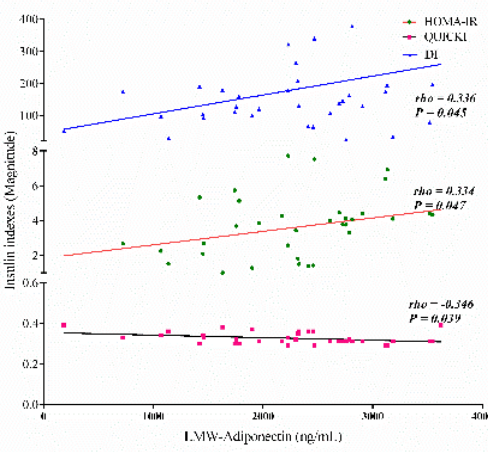

C

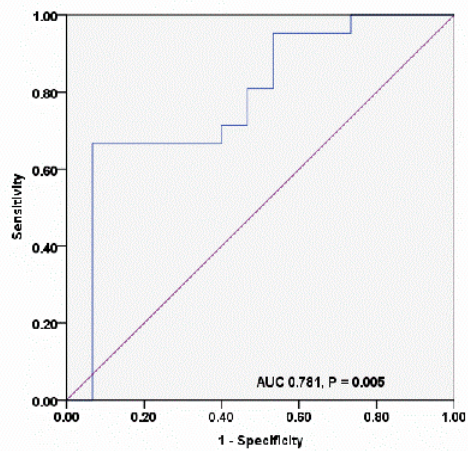

I.MW-Adiponectin ( $\mathrm{ng} / \mathrm{ml}$.)

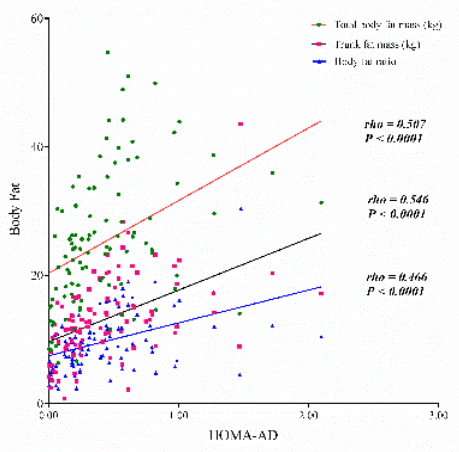

$\mathbf{E}$

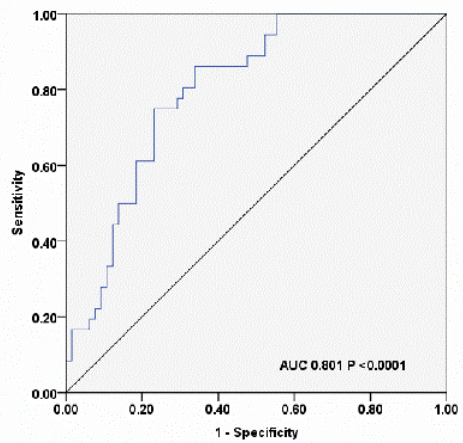

F

HOMA-AD

Figure 3. ROC curves for LMW-Adiponectin matching to insulin resistance indexes and body fat mass. Correlation of LMW-Adiponectin levels with IR indexes: A. whole group, C. group with-obesity. ROC curve of LMW-Adiponectin: B. whole group, D. group with-obesity. E. Correlation of HOMA-AD with body fat mass. F. ROC curve of HOMA-AD in whole group. Rho Spearman's correlation, $\mathrm{P}<0.05$ was consider significant. LMW: low molecular weight; HOMA: homeostasis model assessment; IR: insulin resistance; QUICKI: quantitative insulinsensitivity check index; DI: basal disposition index; AD: adiponectin; ROC: receiver operating characteristic curve; AUC: area under curve

The correlation of RvE1, chemerin, HMW and LMW-Adiponectin levels with the IR setting in our study group is consistent with previous studies indicating that the metabolic changes associated with obesity are largely attributable to the amount of intra-abdominal fat, instead of the amount of total body fat [33-36].

One interesting point of this study is that chemerin is an adipochemokine that can be control by inflammation response itself and has been associated with obesity along other inflammatory diseases [33]. On the other hand, RvE1 is a lipid mediator of which we could explore from two different points of view: the source or the action. Most important, since this is a lipid mediator, it is logical to expect that in obese individuals with present a lipid pool higher lipid in general would present a lower level compared with healthy individuals $[37,38]$.

In addition, most of the information available of RvE1 is associated with its mechanism of action and its pro-resolutive effects. RvE1 has been showed to modulate leukocytes, endothelial activation along other anti-inflammatory properties [38].

One of the concepts of the inflammation present in many chronic diseases such as atherosclerosis or even obesity is that the proresolute mediators are reduced, leading to the persistence of the proinflammatory mediator is and by this way promoting the persistence of the inflammation [37]. Since RvE1 known to modulate inflammation and comes in to play only when inflammation is present, we could expect that the high of RvE1 could be trying to modulate the inflammation. Nevertheless, for some reason it is not enough.

For the best description of the participation of RvE1 and chemerin in the clinical scenario of obesity, it is important to take in consideration the following conceptual points:

in this study it was observe that the high levels of RvE1 were found in individuals with obesity, that these levels were 10-fold higher than chemerin levels, although the affinity of both for their receptor CMKLR1 is not equivalent $[9,39]$. This is evidence that suggests that resolution of the inflammatory process fails even in the subclinical setting.

On the other hand, in the context of obesity-adiposopathy status, the expression of CMKLR1 receptor was up-regulate in the hepatic metabolism by adiponectin levels [18]. This was in accordance with the results obtained in this study: high levels of RvE1 and chemerin and unbalance in the adiponectin levels, and their association with metabolic markers and pathological redistribution of adipose tissue content.

Then we explored the hypothetical combination of the oligomeric components of adiponectin with the HOMA indexes in the early identification of the clinical and metabolic alterations related to IR.

We analyzed whole and group with-obesity; preliminary we found a correlation of LMW-Adiponectin levels with IR indexes. Next, in 
Madrigal-Ruiz PM (2019) The unbalance of adiponectin oligomers, RvE1 and chemerin levels are associate with increase of adiposopathy status and insulin resistance in obesity

the clinical setting of adiposopathy status observed in the individuals included in this study, we used the ROC curves as a useful tool to evaluate the performance of the LMW-Adiponectin levels as a tool to discriminate the IR.

The main differences found were between obesity individuals with and without IR. LMW-Adiponectin is sufficient to distinguish people with IR from those without IR. Another important result was the ability of the HOMA-AD index to show the risk of IR, matching with the correlation with the adiposopathy status [40].

These results highlight the unbalance in the levels of oligomeric adiponectin components, the increase in LMW-Adiponectin while decreasing the HMW-Adiponectin, provided if they exceed the BMI > $30 \mathrm{~kg} / \mathrm{m}^{2}$. However, one limitation of the current study is that we cannot determine the progression of the disease to IR.

Since IR and adiposopathy are characterized by the deposition of ectopic adipose tissue with dysfunctional metabolic properties, and has been associated with adiponectin levels, in people with a wide range of adiposity $[4,40]$. The current study confirms that oligomeric adiponectin levels was as expected, lower in obese individuals and negatively correlated with IR.

At obesity-adiposopathy juncture, obesity was characterized by abnormal production of soluble mediators mainly by adipose tissue and activation of several pro-inflammatory signaling pathways. Such process resulting in the initiation of inflammation, in addition to the crosstalk between immune cells and metabolic organs.

\section{Conclusion}

Individuals with obesity that presented metabolic dysregulation and subclinical inflammatory profile, shown high levels of RvE1 and chemerin associated with their adiposity content, whereas the unbalance of adiponectin oligomers levels are parallel to IR, these facts together result in the ability to discriminate the presence of the absence of the pathogenic process of IR in individuals with obesity. On obesityIR context, this is the first study to link the increased serum levels of three biomarkers (LMW-Adiponectin, RvE1 and chemerin) with adipose content, while a dysmetabolic response was observe.

We propose that LMW-adiponectin/HMW-Adiponectin and RvE1-chemerin relationships favors a specific status of adiposopathy in individuals with obesity. Such measurements could be a new way to early identify individuals with risk factors to insulin resistance.

\section{Funding}

This work was supported by Grant CONACyT FOINS No. 2250-6 "Investigación en Fronteras de la Ciencia 2015-2" 4/XIV-E/2015 FON. INST./276/2016 to MVM/RENH. PNPC-CONACyT UdG Doctoral Training in Biomedical Sciences to FICM 2014-2017 Scholarship No. 305864. Grant No. 237662, UDG-Programa de Fortalecimiento de la Investigación y el Posgrado 2016 to MVM/RENH. Grant PRODEP No. 245256 to PMMR.

\section{Author contributions}

Perla Monserrat Madrigal-Ruiz, Fernanda-Isadora CoronaMeraz, and Rosa-Elena Navarro-Hernández: conceived the study and participated in its design and coordination. Mónica Vazquez-Del Mercado and Perla Monserrat Madrigal-Ruiz were responsible for the classification and clinical evaluation of the individuals included, performed of data base and participated in drafting the paper, and its coordination.
Milton-Omar Guzman-Ornelas, Griselda-Guadalupe MaciasLópez, Gustavo-Ignacio Diaz-Rubio and Fernanda-Isadora CoronaMeraz carried out the assays, performed of data base, and participated in drafting the paper. Milton-Omar Guzman-Ornelas, Marcelo-Heron Petri, and Rosa-Elena Navarro-Hernández performed statistical analysis and interpretation of data. Perla Monserrat Madrigal-Ruiz, Fernanda-Isadora Corona-Meraz, Marcelo-Heron Petri and RosaElena Navarro-Hernández wrote and reviewed the final version of the manuscript. All authors: reviewed, read and approved the final version of the manuscript.

\section{Disclosure}

The authors declare that there is no conflicts of interest regarding the publication of this paper.

\section{References}

1. Appari M, Channon KM, McNeill E (2018) Metabolic regulation of adipose tissue macrophage function in obesity and diabetes. Antioxid Redox Signal 29: 297-312. [Crossref]

2. Patel PS, Buras ED, Balasubramanyam A (2013) The role of the immune system in obesity and insulin resistance. J Obes 2013: 616193. [Crossref]

3. Bays H (2005) Adiposopathy: role of adipocyte factors in a new paradigm. Expert Rev Cardiovasc Ther 3: 187-189. [Crossref]

4. Bays HE (2011) Adiposopathy is "sick fat" a cardiovascular disease? J Am Coll Cardiol 57: 2461-2473. [Crossref]

5. Ernst MC, Sinal CJ (2010) Chemerin: at the crossroads of inflammation and obesity Trends Endocrinol Metab 21: 660-667. [Crossref]

6. Makki K, Froguel P, Wolowczuk I (2013) Adipose tissue in obesity-related inflammation and insulin resistance: cells, cytokines, and chemokines. ISRN Inflamm 2013: 139239. [Crossref]

7. Tilg H, Moschen AR (2006) Adipocytokines: mediators linking adipose tissue, inflammation and immunity. Nat Rev Immunol 6: 772-783.

8. Ray I, Mahata SK, De RK (2016) Obesity: An immunometabolic perspective. Fron Endocrinol (Lausanne) 7: 157. [Crossref]

9. Mariani F, Roncucci L (2015) Chemerin/chemR23 axis in inflammation onset and resolution. Inflamm Res 64: 85-95. [Crossref]

10. Zabel BA, Kwitniewski M, Banas M, Zabieglo K, Murzyn K, et al. (2014) Chemerin regulation and role in host defense. Am J Clin Exp Immunol 3: 1-19. [Crossref]

11. Stojek M (2017) The role of chemerin in human disease. Postepy Hig Med Dosw (Online) 71: 110-117. [Crossref]

12. Takahashi M, Okimura Y, Iguchi G, Nishizawa H, Yamamoto M, et al. (2011) Chemerin regulates $\hat{\mathrm{I}}^{2}$-cell function in mice. Sci Rep 1: 123. [Crossref]

13. Leal Vde O, Mafra D (2013) Adipokines in obesity. Clin Chim Acta 419: 87-94. [Crossref]

14. Nigro E, Scudiero O, Monaco ML, Palmieri A, Mazzarella G, et al. (2014) New insight into adiponectin role in obesity and obesity-related diseases. Biomed Res Int 2014: 658913. [Crossref]

15. Wang ZV, Scherer PE (2016) Adiponectin, the past two decades. J Mol Cell Biol 8 93-100. [Crossref]

16. Laguna-Fernandez A, Checa A, Carracedo M, Artiach G, Petri MH, et al. (2018) ERV1/ ChemR23 signaling protects against atherosclerosis by modifying oxidized low-density lipoprotein uptake and phagocytosis in macrophages. Circulation 138: 1693-1705. [Crossref]

17. Odegaard JI, Chawla A (2011) Alternative macrophage activation and metabolism. Annu Rev Pathol 6: 275-297. [Crossref]

18. Wanninger J, Bauer S, Eisinger K, Weiss TS, Walter R, et al. (2012) Adiponectin upregulates hepatocyte CMKLR1 which is reduced in human fatty liver. Mol Cell Endocrinol 349: 248-254.

19. Ness-Abramof R, Apovian CM (2008) Waist circumference measurement in clinica practice. Nutr Clin Pract 23: 397-404. [Crossref] 
Madrigal-Ruiz PM (2019) The unbalance of adiponectin oligomers, RvE1 and chemerin levels are associate with increase of adiposopathy status and insulin resistance in obesity

20. Pajunen P, Rissanen H, Laaksonen MA, Heliovaara M, Reunanen A, et al. (2013) Sagittal abdominal diameter as a new predictor for incident diabetes. Diabetes Care 36: $283-288$.

21. Shen S, Lu Y, Qi H, Li F, Shen Z, et al. (2017) Waist-to-height ratio is an effective indicator for comprehensive cardiovascular health. Sci Rep 7: 43046. [Crossref]

22. Garaulet M, Hernandez-Morante JJ, Tebar FJ, Zamora S, Canteras M (2006) Twodimensional predictive equation to classify visceral obesity in clinical practice. Obesity (Silver Spring) 14: 1181-1191

23. Wu J, Gong L, Li Q, Hu J, Zhang S, et al. (2017) A novel visceral adiposity index for prediction of type 2 diabetes and pre-diabetes in chinese adults: A 5-year prospective study. Sci Rep 7: 13784. [Crossref]

24. Guerrero-Romero F, Rodriguez-Moran M (2003) Abdominal volume index. An anthropometry-based index for estimation of obesity is strongly related to impaired glucose tolerance and type 2 diabetes mellitus. Arch Med Res 34: 428-432.

25. Friedewald WT, Levy RI, Fredrickson DS (1972) Estimation of the concentration of low-density lipoprotein cholesterol in plasma, without use of the preparative ultracentrifuge. Clin Chem 18: 499-502. [Crossref]

26. Wintrobe MM, Landsberg JW (2013) A standardized technique for the blood sedimentation test. 1935. Am J Med Sci 346: 148-153. [Crossref]

27. Vilela BS, Vasques AC, Cassani RS, Forti AC, et al. (2016) The HOMA-Adiponectin (HOMA-AD) closely mirrors the homa-ir index in the screening of insulin resistance in the brazilian metabolic syndrome study (BRAMS). PLoS One 11: e 0158751. [Crossref]

28. Patarrao RS, Wayne Lautt W, Paula Macedo M (2014) Assessment of methods and indexes of insulin sensitivity. Revista portuguesa de endocrinologia, diabetes e metabolismo 9: 65-73.

29. Maurizi G, Della Guardia L, Maurizi A, Poloni A (2018) Adipocytes properties and crosstalk with immune system in obesity-related inflammation. J Cell Physiol 233: 8897. [Crossref]
30. Trim W, Turner JE, Thompson D (2018) Parallels in immunometabolic adipose tissue dysfunction with ageing and obesity. Front Immunol 9: 169. [Crossref]

31. Bluher M (2013) Adipose tissue dysfunction contributes to obesity related metabolic diseases. Best Pract Res Clin Endocrinol Metab 27: 163-177.

32. Tomkin GH, Owens D (2017) Diabetes and dyslipidemia: characterizing lipoprotein metabolism. Diabetes Metab Syndr Obes 10: 333-343. [Crossref]

33. Habib SS, Eshki A, AlTassan B, Fatani D, Helmi H, et al. (2017) Relationship of serum novel adipokine chemerin levels with body composition, insulin resistance, dyslipidemia and diabesity in Saudi women. Eur Rev Med Pharmacol Sci 21: 12961302. [Crossref]

34. Balsan GA, Vieira JL, Oliveira AM, Portal VL (2015) Relationship between adiponectin, obesity and insulin resistance. Rev Assoc Med Bras 61: 72-80.

35. Jung UJ, Choi MS (2014) Obesity and its metabolic complications: the role of adipokines and the relationship between obesity, inflammation, insulin resistance, dyslipidemia and nonalcoholic fatty liver disease. Int J Mol Sci 15: 6184-6223.

36. Li Y, Shi B, Li S (2014) Association between serum chemerin concentrations and clinical indices in obesity or metabolic syndrome: a meta-analysis. PLoS One 9: e113915. [Crossref]

37. Ho KJ, Spite M, Owens CD, Lancero H, Kroemer AH, et al. (2010) Aspirin-triggered lipoxin and resolvin E1 modulate vascular smooth muscle phenotype and correlate with peripheral atherosclerosis. Am J Pathol 177: 2116-2123.

38. Lim JY, Park CK, Hwang SW (2015) Biological roles of resolvins and related substances in the resolution of pain. Biomed Res Int 2015: 830930. [Crossref]

39. Kennedy AJ, Davenport AP (2018) International union of basic and clinical pharmacology CIII: Chemerin receptors CMKLR1 (Chemerin1) and GPR1 (Chemerin2) nomenclature, pharmacology, and function. Pharmacol Rev 70: 174-196. [Crossref]

40. Farb MG, Gokce N (2015) Visceral adiposopathy: A vascular perspective. Horm Mol Biol Clin Investig 21: 125-136. [Crossref]

Copyright: (C2019 Madrigal-Ruiz PM. This is an open-access article distributed under the terms of the Creative Commons Attribution License, which permits unrestricted use, distribution, and reproduction in any medium, provided the original author and source are credited. 